\title{
Alpha Klotho and phosphate homeostasis
}

\author{
A. Bian $\cdot$ C. Xing $\cdot$ M. C. Hu
}

Received: 1 August 2014 / Accepted: 8 August 2014 / Published online: 7 September 2014

(C) Italian Society of Endocrinology (SIE) 2014

Keywords $\alpha$ Klotho $\cdot$ Phosphate homeostasis $\cdot \mathrm{Na}$ dependent phosphate $(\mathrm{NaPi})$ co-transporter $\cdot$ Chronic kidney disease

\section{Introduction}

Alpha-Klotho ( $\alpha$ Klotho) and fibroblast growth factor23 (FGF23) were independently discovered in 1997 [1] and 2000 [2] and were identified as an anti-aging protein and a novel phosphatonin, respectively. Interestingly, the FGF23null mouse phenocopies almost all features of the $\alpha$ Klothonull mouse suggesting that $\alpha$ Klotho and FGF23 may share common signaling pathways at least in the maintenance of mineral metabolism [3]. In vitro experiments further confirmed that membrane $\alpha$ Klotho functions as a mandatory co-receptor for FGF23 along with the FGF receptor (FGFR) to transduce FGF23 signaling to modulate calcium and phosphate metabolism as a calciophosphotropic hormone $[4,5]$.

A. Bian - M. C. Hu

Charles and Jane Pak Center for Mineral Metabolism and Clinical Research, University of Texas Southwestern Medical Center, Dallas, USA
A. Bian $\cdot$ C. Xing
Department of Nephrology, First Affiliated Hospital of Nanjing
Medical University, Nanjing, Jiangsu, PR of China
M. C. Hu $(\bowtie)$
Department of Internal Medicine, Charles and Jane Pak Center for Mineral Metabolism and Clinical Research, University of Texas Southwestern Medical Center, 5323 Harry Hines Blvd, Dallas, TX 75390-885, USA
e-mail: ming-chang.hu@utsouthwestern.edu

The identification of $\alpha$ Klotho as co-receptor of FGF23 has broadened our understanding of mineral metabolism. Emerging evidence suggests that $\alpha$ Klotho also acts independently of FGF23 as a phosphate regulator. $\alpha$ Klotho contributes to phosphate homeostasis via interplay with other calciophosphotropic hormones (parathyroid hormone, FGF23, and 1,25-[OH] $]_{2}$ vitamin D) in the kidney, bone, intestine, and parathyroid gland. $\alpha$ Klotho deficiency triggers and aggravates deranged mineral metabolism, secondary hyperparathyroidism, vascular calcification, cardiac hypertrophy and fibrosis, and kidney fibrosis as evident in chronic kidney disease (CKD) and end-stage renal disease (ESRD). This review will update current understanding of $\alpha$ Klotho and its contribution to maintenance of phosphate homeostasis. The contribution of $\alpha$ Klotho to aging, acute kidney injury and chronic kidney disease has been recently reviewed [6-13].

\section{Overview of phosphate homeostasis}

Phosphorus, its element of phosphate, is the 6th most abundant element in the human being. About $1 \%$ of body phosphate is present in extracellular fluid. Serum phosphate serves as an exchange pool among various phosphate-regulating organs (kidney, intestine, and bone) [9, 14]. Fecal and urine phosphate excretion is a major way to maintain phosphate homeostasis through a complicated, but tightly and efficiently regulated network consisting of several calciophosphotropic hormones (PTH, FGF23, 1,25-[OH] vitamin D) which are dedicated to both calcium and phosphate regulation [15-17].

FGF23, known as a phosphatonin, is predominantly synthesized in osteocytes and osteoblasts [12, 18-20]. It is regulated by dietary phosphate intake, serum phosphate, 
1,25- $(\mathrm{OH})_{2}$ vitamin $\mathrm{D}, \mathrm{PTH}$, and $\alpha$ Klotho, and mainly targets FGFRs through formation of a tertiary complex with membrane $\alpha$ Klotho protein to inhibit renal phosphate reabsorption by decreasing NaPi transport activity and to suppress $1,25-(\mathrm{OH})_{2}$ vitamin $\mathrm{D}$ production in the kidney [2125]. FGF23 also decreases PTH production, which in turn decreases bone turnover $[12,26]$.

Synthesized by chief cells in parathyroid glands, PTH responses directly to extracellular calcium concentration via calcium-sensing receptor and changes in PTH mRNA stability $[27,28]$. PTH acts as phosphaturic hormone, reducing tubular phosphate reabsorption through promoting endocytosis of the Na-coupled phosphate transporters $\mathrm{NaPi}-2 \mathrm{a}$ and $2 \mathrm{c}$ in proximal tubular epithelial cells, thus increasing urinary phosphate excretion [29-31]. PTH also modulates bone turnover, contributing to calcium and phosphate homeostasis of the skeleton [32]. In early stage of hyperparathyroidism, PTH stimulates bone release of calcium and phosphate, enhances intestinal absorption of calcium and phosphate, and increases renal calcium reabsorption while decreasing urinary phosphate reabsorption, thus maintaining a relatively normal serum phosphate concentration [33]. High PTH can stimulate the secretion of 1,25$(\mathrm{OH})_{2}$ vitamin D and FGF23 [12].

$1,25-(\mathrm{OH})_{2}$ vitamin $\mathrm{D}$, whose production is suppressed by membrane $\alpha$-Klotho $[8,15]$, activates intestinal calcium and phosphate absorption. However, active vitamin D stimulates $\alpha$-Klotho production in the kidney. Independent of changes in intestinal calcium absorption and serum calcium, 1,25- $(\mathrm{OH})_{2}$ vitamin D represses the transcription of $P T H$ by associating with the vitamin D receptor, decreasing renal excretion of phosphate [34]. High vitamin D may also decrease FGF23 levels, further limiting phosphate excretion [12].

$\alpha$ Klotho is predominantly expressed in renal distal convoluted tubules with lower abundance in proximal convoluted tubules, and also in parathyroid chief cells, making the kidney and parathyroid gland the primary FGF23 target organs $[26,35]$. FGF23, without the participation of $\alpha$ Klotho, fails to regulate phosphate homeostasis. When HEK293 cells are co-transfected with a $\alpha$ Klotho and FGFRs, they acquire the ability to respond to FGF23 and activate FGF signaling [36]. Both FGF23-deficient [36] and $\alpha$ Klotho-deficient mice $[1,37]$ showed increased serum levels of phosphate and $1,25-(\mathrm{OH})_{2}$ vitamin $\mathrm{D}$, which may result from impaired suppression of cyp27b1 [38] and NaPi activity [35, 39]. Both circulating soluble $\alpha$ Klotho and membrane $\alpha$ Klotho can suppress the secretion of PTH and 1,25- $(\mathrm{OH})_{2}$ vitamin $\mathrm{D}$, thus indirectly influencing the production of FGF23 $[8,15]$. Whether $\alpha$ Klotho directly modulates FGF23 production in the bone remains to be confirmed.

Taken together, almost all players implicated in phosphate homeostasis are $\mathrm{PTH}, 1,25(\mathrm{OH})_{2}$ vitamin $\mathrm{D}, \mathrm{FGF} 23$, and $\alpha$ Klotho that regulate phosphate metabolism independently and are also highly interrelated through modulation of other hormones' metabolism.

\section{Role of abnormal $\alpha$ Klotho in disturbed phosphate metabolism}

$\alpha$ Klotho deficiency

The role of $\alpha$ Klotho in phosphate homeostasis was recognized as soon as $\alpha$ Klotho was discovered because the $\alpha$ Klotho-deficient mouse demonstrates severe hyperphosphatemia [1]. This was further confirmed by the fact that there is low serum phosphate in $\alpha$ Klotho-overexpressing mice [40]. A patient with homozygous missense mutation (H193R) in the $\alpha$ KLOTHO gene had severe calcinosis, dural and carotid artery calcifications, severe hyperphosphatemia, hypercalcemia, and high serum 1,25-(OH $)_{2}$ vitamin D and FGF23 [41]. This mutation conceivably destabilizes KL1 domain of $\alpha$ Klotho, thereby attenuating production of membrane-bound and soluble $\alpha$ Klotho protein [41]. Therefore, $\alpha$ KLOTHO is a novel candidate gene for genetic hyperphosphatemia and calcinosis.

Emerging evidence in CKD and ESRD showed that kidney disease is a status of $\alpha$ Klotho deficiency. Although the mechanism of reduced circulating $\alpha$ Klotho is largely unclear, it is conceivable that $\alpha$ Klotho deficiency might be involved in the development of CKD-mineral bone disease (CKD-MBD): hyperphosphatemia, hyperparathyroidism, and vascular calcification. Hopefully $\alpha$ Klotho administration will be a novel strategy for CKD-MBD [7, 42].

$\alpha$ Klotho overexpression

It is interesting to note that extremely high-circulating $\alpha$ Klotho does not necessarily have better impact on mineral metabolism. In 2008, Brownstein and colleagues reported one case featuring hypophosphatemic rickets, hyperparathyroidism, $>10$ - to 20 -fold higher circulating $\alpha$ Klotho due to a balanced chromosomal translocation between $9 \mathrm{q} 21.13$ and $13 q 13.1$ [43]. Unexpectedly, there were higher levels of circulating FGF23 and PTH which can trigger or exacerbate hypophosphatemia and osteodystrophy [43]. Up to now, the mechanism of $\alpha$ Klotho-induced elevation of these two phosphotropic hormones still has not been completely elucidated.

Similar phenotypic features were seen in mice with adenovirally delivered soluble $\alpha$ Klotho gene [44]. Mice had extremely high levels of circulating $\alpha$ Klotho (5- to 20-fold normal) and exhibited hypophosphatemia, hypocalcemia, reduced bone mineral content, expanded growth plates, and severe osteomalacia, and fracture. In addition, these 
Table 1 Effect of $\alpha$ Klotho on Na-dependent phosphate cotransporters

\begin{tabular}{|c|c|c|c|c|}
\hline \multirow[t]{2}{*}{ Isoforms } & \multirow[t]{2}{*}{ Substrates } & \multirow[t]{2}{*}{ Expression location } & \multicolumn{2}{|l|}{$\alpha$ Klotho effect } \\
\hline & & & Expression abundance & Transport activity \\
\hline $\mathrm{NaPi}-2 \mathrm{a}$ & $3 \mathrm{Na}^{+} / \mathrm{HPO}_{4}{ }^{2-}$ & $\begin{array}{l}\text { Kidney: } \mathrm{S} 1,2,3 \\
\text { bone: osteoblast }\end{array}$ & $\begin{array}{l}\downarrow \\
\text { N/a }\end{array}$ & $\begin{array}{l}\downarrow \\
\text { N/a }\end{array}$ \\
\hline $\mathrm{NaPi}-2 \mathrm{~b}$ & $3 \mathrm{Na}^{+} / \mathrm{HPO}_{4}{ }^{2-}$ & $\begin{array}{l}\text { Intestine: enterocytes in duodenum and jejunum } \\
\text { Bone: only mRNA detected }\end{array}$ & $\begin{array}{l}\downarrow \\
\text { N/a }\end{array}$ & $\begin{array}{l}\downarrow \\
\text { N/a }\end{array}$ \\
\hline $\mathrm{NaPi}-2 \mathrm{c}$ & $2 \mathrm{Na}^{+} / \mathrm{HPO}_{4}{ }^{2-}$ & Kidney: S1, S2 & $\downarrow$ & N/a \\
\hline PiT-1 & $2 \mathrm{Na}^{+} / \mathrm{H}_{2} \mathrm{PO}_{4}^{-}$ & $\begin{array}{l}\text { Kidney: only mRNA detected } \\
\text { Intestine: enterocytes in duodenum and jejunum } \\
\text { Bone: osteoblast } \\
\text { Artery: smooth muscle cell }\end{array}$ & $\begin{array}{l}\text { N/a } \\
\text { N/a } \\
\text { N/a } \\
\downarrow\end{array}$ & $\begin{array}{l}\text { N/a } \\
\text { N/a } \\
\text { N/a } \\
\downarrow\end{array}$ \\
\hline PiT-2 & $2 \mathrm{Na}^{+} / \mathrm{H}_{2} \mathrm{PO}_{4}^{-}$ & $\begin{array}{l}\text { Kidney: S1, S2 } \\
\text { Intestine: only mRNA detected } \\
\text { Bone: osteoblast with low abundance }\end{array}$ & $\begin{array}{l}\text { N/a } \\
\text { N/a } \\
\text { N/a }\end{array}$ & $\begin{array}{l}\mathrm{N} / \mathrm{a} \\
\mathrm{N} / \mathrm{a} \\
\mathrm{N} / \mathrm{a}\end{array}$ \\
\hline
\end{tabular}

$\mathrm{S}$, segment of the proximal tubule which is subdivided into three segments present in the cortical labyrinth and the medullar rays; S1, first portion of proximal convoluted tubule; S2, latter portion of proximal convoluted tubule and first portion of proximal straight tubule; S3, latter portion of proximal straight tubule

mice had markedly elevated level of FGF23 (38- to 456fold) in the circulation, and Fgf 23 mRNA (>150-fold) in bone. Therefore, soluble $\alpha$ Klotho protein in very high levels potently stimulates FGF23 production through yet-to-be identified mechanism [44].

Taken together, modulation of circulating $\alpha$ Klotho within a desired range is required for the maintenance of phosphate balance to protect against phosphate toxicity. Both pathological increase and decrease in circulating $\alpha$ Klotho can cause disturbed phosphate homeostasis. Obviously, many clinical features in the patient with lossof-function mutation in $\alpha K L O T H O$ gene [41] and in the patient with gain-of-function translocation of $\alpha K L O T H O$ gene [44] differ from those in $\alpha$ Klotho-deficient [1] or $\alpha$ Klotho-overexpressing mice [40], but the mechanism remains unexplained.

\section{$\alpha$ Klotho effect on Na-dependent phosphate cotransporters}

External phosphate balance is achieved through modulation of intestinal uptake of phosphate from diet, and renal reabsorption of phosphate from urine via regulation of $\mathrm{NaPi}$ activity. Type II (SLCA34) and type III (SLC20) Nacoupled phosphate transporters are responsible for uptake of extracellular phosphate [45-47]. The type II transporters $\mathrm{NaPi}-2 \mathrm{a}$ and $\mathrm{NaPi}-2 \mathrm{c}$ play a major role in phosphate reabsorption in the kidney and $\mathrm{NaPi}-2 \mathrm{~b}$ mediates phosphate absorption in the intestine. Type III cotransporters including PiT-1 and PiT-2 are expressed in more broad tissues. PiT-1 also exists in bone and kidney and PiT-2 in intestine and bone. They are assumed to participate in control of phosphate absorption in the intestine, phosphate reabsorption and excretion in the kidney, and phosphate release and storage in the bone [45-48] (Table 1). Note that both $\mathrm{NaPi}-\mathrm{II}$ and III isoforms control phosphate influx across the apical membrane, but the mechanism of phosphate efflux across the basolateral membrane remains to be identified.

$\alpha$ Klotho regulation of phosphate transport in the kidney

In the kidney, in addition to $\mathrm{NaPi}-2 \mathrm{a}$ and $2 \mathrm{c}$ whose expression pattern and function have been well characterized in proximal tubules, mRNA of both PiT-1 and PiT-2 was also detected, but only PiT-2 protein and its function in proximal tubular epithelia were noted [49, 50]. After a high phosphate diet, rats showed marked increase in serum phosphate with gradual down-regulation of phosphate reabsorption mediated by decrease in $\mathrm{NaPi}-2 \mathrm{a}(<1 \mathrm{~h})$ followed by delayed and eventual down-regulation of PiT-2 $(>8 \mathrm{~h})$ and $\mathrm{NaPi}-2 \mathrm{c}(>24 \mathrm{~h})$ [51]. NaPi-2a- and NaPi-2c-mediated transport is suppressed by $32 \%$ and PiT2-mediated transport by $73 \%$, with phosphate loading, which proves PiT-2 to be highly regulated at an intermediate time course between NaPi-2a and $\mathrm{NaPi}-2 \mathrm{c}$ [51]. The biological function of PiT-1 in the renal phosphate transport is uncharacterized.

$\alpha$ Klotho deficiency up-regulates, and $\alpha$ Klotho overexpression or supplementation down-regulates $\mathrm{NaPi}-2 \mathrm{a}$ expression in the kidney and NaPi transport activity (Fig. 1) [35, $39,52]$. In addition, $\alpha$ Klotho deficiency is associated with up-regulation of NaPi-2c in the kidney [54], which should exacerbate hyperphosphatemia in $\alpha$ Klotho-deficient mice.

More interestingly, circulating soluble $\alpha$ Klotho can directly suppress $\mathrm{NaPi}$ transport activity, because $\alpha$ Klotho does so when directly added to cultured proximal 


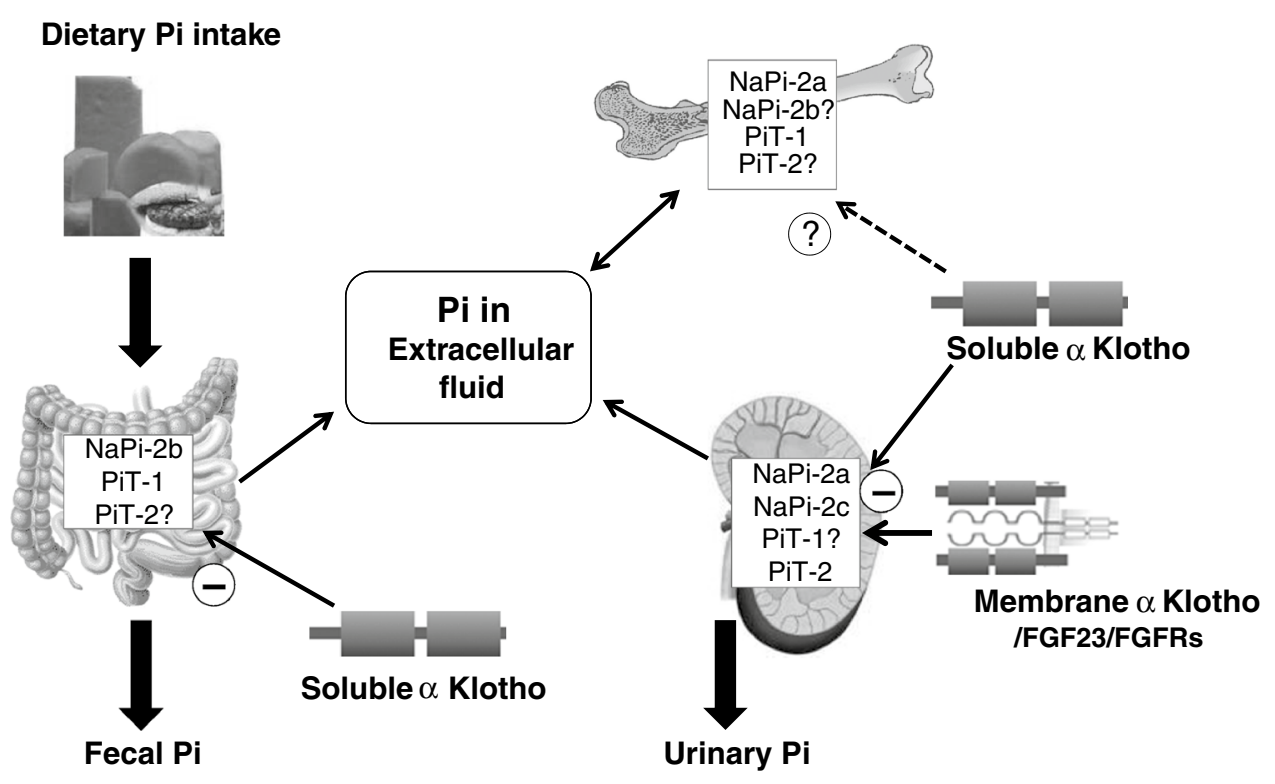

Fig. $1 \alpha$ Klotho inhibits Na-dependent phosphate co-transporters. Phosphate absorption from food is regulated by NaPi-2b and PiT-1 in small intestine, and phosphate reabsorption from urine by $\mathrm{NaPi}$ 2a, 2c and PiT-2 in renal proximal tubules. Gut and kidney are the two major organs to modulate phosphate excretion based on dietary intake and phosphate concentration in extracellular fluid, which is also maintained by phosphate trafficking across bone controlled by $\mathrm{NaPi}-2 \mathrm{a}$ and PiT-1 in osteoblast. Membrane $\alpha$ Klotho can regulate urinary phosphate excretion through FGF23 signaling pathway. In addition, soluble $\alpha$ Klotho can also exert phosphaturic action via a

tubule-like cells, and in cell-free brush border membrane vesicles (BBMV) without FGF23. The fact that FGF23 null mice preserve the ability to increase urine phosphate excretion in response to soluble $\alpha$ Klotho [35] further supports that $\alpha$ Klotho also has FGF23-independent pathway to induce phosphaturia. $\alpha$ Klotho appears to function as glycosidase acting on a yet unknown substrate in the brush border, since glucuronidase inhibitor can reverse $\alpha$ Klotho's action on NaPi transport in both BBMV and cultured cells. Chronic effect of $\alpha$ Klotho on inhibition of NaPi-2a is associated with induction of NaPi-2a internalization and degradation through modification of moieties of sugar chain in NaPi-2a [35]. Thus far, mechanism of $\alpha$ Klotho effect on $\mathrm{NaPi}-2 \mathrm{c}$ is still completely elusive.

$\alpha$ Klotho effect on phosphate transport in the intestine

In the duodenum and jejunum, expression of $\mathrm{NaPi}-2 \mathrm{~b}$ and both type III cotransporter isoforms (PiT-1 and PiT-2) has been reported [53, 54]. In mice, the functional NaPi-2b, PiT-1 and PiT2 are also present in ileum [55], but NaPi$2 \mathrm{~b}$ and PiT-1 are thought to be most active in modulating intestinal phosphate absorption. In comparison with PiT-1, $\mathrm{NaPi}-2 \mathrm{~b}$ is the major transporter that mediates phosphate
FGF23-independent manner to directly modulate NaPi-2a activity. The role of $\alpha$ Klotho in modulation of bone formation is known but $\alpha$ Klotho protein is not expressed in bone; soluble $\alpha$ Klotho is therefore considered an alternative candidate. How soluble $\alpha$ Klotho affects $\mathrm{NaPi}$ transport activity in the bone has not been addressed, although $\alpha$ Klotho has been shown to suppress $\mathrm{NaPi}-2 \mathrm{a}$ expression and activity in proximal tubules and PiT-1 expression and activity in vascular smooth muscle cells. Therefore, it is still premature to conclude that $\alpha$ Klotho can directly affect bone development and mineralization

absorption [53]. The $\alpha$ Klotho-deficient mice displayed an increased activity of intestinal $\mathrm{NaPi}$ transport, and increased levels of $\mathrm{NaPi}-2 \mathrm{~b}$ protein compared with $W T$ mice [52], indicating that up-regulation of $\mathrm{NaPi}-2 \mathrm{~b}$ protein and activity may be one of the molecular mechanisms of hyperphosphatemia in $\alpha$ Klotho-deficient mice. The fact that co-expression of $\alpha$ Klotho decreased phosphate-induced current in NaPi-2b-expressing Xenopus oocytes [56] further supports that $\alpha$ Klotho directly down-regulates NaPi-2b activity (Fig. 1). But the effect of $\alpha$ Klotho on PiT-1 in the intestine needs to be identified.

$\alpha$ Klotho effect on the phosphate transport in the bone

Bone does not only provide mechanical support, but also contributes to the maintenance of circulating phosphate and calcium as a target organ of several calciophosphotropic hormones such as $1,25-(\mathrm{OH})_{2}$ vitamin $\mathrm{D}, \mathrm{PTH}, \mathrm{FGF} 23$, and $\alpha$ Klotho, and as an organ producing FGF23.

There is high PiT-1 mRNA with low PiT-2 mRNA abundance in osteoblasts [57]. Only PiT-1 rather PiT-2 mRNA was up-regulated by phosphate deprivation and $\mathrm{Ca}^{2+}$ treatment, which suggests that PiT-1 may play a more important role in phosphate trafficking across the bone [58]. Both 
$\mathrm{NaPi}-2 \mathrm{a}$ and $\mathrm{NaPi}-2 \mathrm{~b}$ were recently found in osteoblast-like cell lines and play a role in phosphate flux to modulate mineralization [59]. But their responses to phosphate challenge differed, as phosphate supplementation only up-regulated $\mathrm{NaPi}-2 \mathrm{a}$, and not $\mathrm{NaPi}-2 \mathrm{~b}$; whereas phosphate deprivation did not change either one. Whether these isoforms play distinct roles in phosphate trafficking across the bone individually, or in concert at different scenarios, remains to be explored.

The osteopenia in $\alpha$ Klotho-deficient mice has been recognized for more than one decade [1, 60-62]. However, there is no $\alpha$ Klotho protein expression in the bone; soluble $\alpha$ Klotho may be, therefore, a contributor to maintenance of bone formation (Fig. 1).

\section{Conclusive remarks}

Several lines of emerging evidence suggest that $\alpha$ Klotho deficiency and hyperphosphatemia are considered as risks for the high morbidity and mortality of cardiovascular diseases in CKD/ESRD [7, 63-71]. Therefore, the potential indication for $\alpha$ Klotho therapy will be genetic and acquired hyperphosphatemia such as CKD/ESRD. Better understanding of $\alpha$ Klotho physiology and pathophysiology will help to develop new drugs that may correct hyperphosphatemia and hypo- $\alpha$ Klotho-temia and to improve longterm outcome of $\mathrm{CKD} / \mathrm{ESRD}$ patients.

Acknowledgments The authors acknowledge grant support from the NIH (R01-DK091392, R01-DK092461), The George M. O'Brien Kidney Research Center at UT Southwestern Medical Center (P30DK-07938), and the Charles and Jane Pak Research Foundation. Ao Bian was in part supported by Visiting Scholar Award from National Natural Science Foundation of China (81170660H0509, 81270408H0220), and Provincial Natural Science Foundation of Jiangsu, China (BK2011849). The authors thank Dr. Orson Moe for helpful discussions.

Conflict of interest There are no conflicts of interest.

\section{References}

1. Kuro-o M, Matsumura Y, Aizawa $\mathrm{H}$ et al (1997) Mutation of the mouse klotho gene leads to a syndrome resembling ageing. Nature 390:45-51

2. ADHR Consortium (2000) Autosomal dominant hypophosphataemic rickets is associated with mutations in FGF23. Nat Genet 26:345-348

3. Razzaque MS, Lanske B (2006) Hypervitaminosis D and premature aging: lessons learned from FGF23 and Klotho mutant mice. Trends Mol Med 12:298-305

4. Kuro-o M (2006) Klotho as a regulator of fibroblast growth factor signaling and phosphate/calcium metabolism. Curr Opin Nephrol Hypertens 15:437-441

5. Urakawa I, Yamazaki Y, Shimada T et al (2006) Klotho converts canonical FGF receptor into a specific receptor for FGF23. Nature 444:770-774
6. Tan SJ, Smith ER, Hewitson TD et al (2014) The importance of klotho in phosphate metabolism and kidney disease. Nephrology (Carlton) 19:439-449

7. Olauson H, Larsson TE (2013) FGF23 and Klotho in chronic kidney disease. Curr Opin Nephrol Hypertens 22:397-404

8. Hu MC, Kuro-o M, Moe OW (2013) Klotho and chronic kidney disease. Contrib Nephrol 180:47-63

9. Hu MC, Shiizaki K, Kuro-o M et al (2013) Fibroblast growth factor 23 and Klotho: physiology and pathophysiology of an endocrine network of mineral metabolism. Annu Rev Physiol 75:503-533

10. Hu MC, Kuro-o M, Moe OW (2012) Secreted klotho and chronic kidney disease. Adv Exp Med Biol 728:126-157

11. Kuro-o M (2010) A potential link between phosphate and aging-lessons from Klotho-deficient mice. Mech Ageing Dev 131:270-275

12. Quarles LD (2012) Skeletal secretion of FGF-23 regulates phosphate and vitamin D metabolism. Nat Rev Endocrinol 8:276-286

13. Razzaque MS (2009) The FGF23-Klotho axis: endocrine regulation of phosphate homeostasis. Nat Rev Endocrinol 5:611-619

14. Berner YN, Shike M (1988) Consequences of phosphate imbalance. Annu Rev Nutr 8:121-148

15. Hu MC, Kuro-o M, Moe OW (2013) Renal and extrarenal actions of Klotho. Semin Nephrol 33:118-129

16. Huang CL, Moe OW (2011) Klotho: a novel regulator of calcium and phosphorus homeostasis. Pflugers Arch 462:185-193

17. Takenaka $T$, Watanabe $Y$, Inoue $T$ et al (2013) Fibroblast growth factor 23 enhances renal klotho abundance. Pflugers Arch 465:935-943

18. Feng JQ, Ye L, Schiavi S (2009) Do osteocytes contribute to phosphate homeostasis? Curr Opin Nephrol Hypertens 18:285-291

19. Feng JQ, Clinkenbeard EL, Yuan B et al (2013) Osteocyte regulation of phosphate homeostasis and bone mineralization underlies the pathophysiology of the heritable disorders of rickets and osteomalacia. Bone 54:213-221

20. Bonewald LF, Wacker MJ (2013) FGF23 production by osteocytes. Pediatr Nephrol 28:563-568

21. Quarles LD (2012) Role of FGF23 in vitamin D and phosphate metabolism: implications in chronic kidney disease. Exp Cell Res 318:1040-1048

22. Shimada T, Kakitani M, Yamazaki Y et al (2004) Targeted ablation of Fgf23 demonstrates an essential physiological role of FGF23 in phosphate and vitamin D metabolism. J Clin Invest 113:561-568

23. Shimada T, Yamazaki Y, Takahashi M et al (2005) Vitamin D receptor-independent FGF23 actions in regulating phosphate and vitamin D metabolism. Am J Physiol Renal Physiol 289:F1088-F1095

24. Gattineni J, Twombley K, Goetz R et al (2011) Regulation of serum $1,25(\mathrm{OH}) 2$ vitamin D3 levels by fibroblast growth factor 23 is mediated by FGF receptors 3 and 4. Am J Physiol Renal Physiol 301:F371-F377

25. Gattineni J, Alphonse P, Zhang Q et al (2014) Regulation of renal phosphate transport by FGF23 is mediated by FGFR1 and FGFR4. Am J Physiol Renal Physiol 306:F351-F358

26. Ben-Dov IZ, Galitzer H, Lavi-Moshayoff V et al (2007) The parathyroid is a target organ for FGF23 in rats. J Clin Invest 117:4003-4008

27. Kilav R, Silver J, Naveh-Many T (1995) Parathyroid hormone gene expression in hypophosphatemic rats. J Clin Invest 96:327-333

28. Naveh-Many T, Rahamimov R, Livni N et al (1995) Parathyroid cell proliferation in normal and chronic renal failure rats. The effects of calcium, phosphate, and vitamin D. J Clin Invest 96:1786-1793

29. Gattineni J, Baum M (2012) Genetic disorders of phosphate regulation. Pediatr Nephrol 27:1477-1487 
30. Forster IC, Hernando N, Biber J et al (2006) Proximal tubular handling of phosphate: a molecular perspective. Kidney Int 70:1548-1559

31. Biber J, Hernando N, Forster I (2013) Phosphate transporters and their function. Annu Rev Physiol 75:535-550

32. Evenepoel P, Rodriguez M, Ketteler M (2014) Laboratory abnormalities in CKD-MBD: markers, predictors, or mediators of disease? Semin Nephrol 34:151-163

33. Lederer E (2014) Regulation of serum phosphate. J Physiol. (in press)

34. Kumar R, Thompson JR (2011) The regulation of parathyroid hormone secretion and synthesis. J Am Soc Nephrol 22:216-224

35. Hu MC, Shi M, Zhang J et al (2010) Klotho: a novel phosphaturic substance acting as an autocrine enzyme in the renal proximal tubule. FASEB J 24:3438-3450

36. Kurosu H, Ogawa Y, Miyoshi M et al (2006) Regulation of fibroblast growth factor-23 signaling by klotho. J Biol Chem 281:6120-6123

37. Tsujikawa H, Kurotaki Y, Fujimori T et al (2003) Klotho, a gene related to a syndrome resembling human premature aging, functions in a negative regulatory circuit of vitamin D endocrine system. Mol Endocrinol 17:2393-2403

38. Woudenberg-Vrenken TE, van der Eerden BC, van der Kemp AW et al (2012) Characterization of vitamin D-deficient klotho ${ }^{-1-}$ mice: do increased levels of serum 1,25(OH)2D3 cause disturbed calcium and phosphate homeostasis in $\mathrm{klotho}^{-1-}$ mice? Nephrol Dial Transplant 27:4061-4068

39. Nakatani T, Ohnishi M, Razzaque MS (2009) Inactivation of klotho function induces hyperphosphatemia even in presence of high serum fibroblast growth factor 23 levels in a genetically engineered hypophosphatemic (Hyp) mouse model. FASEB J 23:3702-3711

40. Kurosu H, Yamamoto M, Clark JD et al (2005) Suppression of aging in mice by the hormone Klotho. Science 309:1829-1833

41. Ichikawa S, Imel EA, Kreiter ML et al (2007) A homozygous missense mutation in human KLOTHO causes severe tumoral calcinosis. J Clin Invest 117:2684-2691

42. Drueke TB, Massy ZA (2013) Circulating Klotho levels: clinical relevance and relationship with tissue Klotho expression. Kidney Int 83:13-15

43. Brownstein CA, Adler F, Nelson-Williams C et al (2008) A translocation causing increased alpha-klotho level results in hypophosphatemic rickets and hyperparathyroidism. Proc Natl Acad Sci USA 105:3455-3460

44. Smith RC, O'Bryan LM, Farrow EG et al (2012) Circulating alphaKlotho influences phosphate handling by controlling FGF23 production. J Clin Invest 122:4710-4715

45. Werner A, Dehmelt L, Nalbant $\mathrm{P}(1998) \mathrm{Na}^{+}$-dependent phosphate cotransporters: the NaPi protein families. J Exp Biol 201:3135-3142

46. Miyamoto K, Segawa H, Ito M et al (2004) Physiological regulation of renal sodium-dependent phosphate cotransporters. Jpn J Physiol 54:93-102

47. Sabbagh Y, Giral H, Caldas Y et al (2011) Intestinal phosphate transport. Adv Chronic Kidney Dis 18:85-90

48. Forster IC, Hernando N, Biber J et al (2013) Phosphate transporters of the SLC20 and SLC34 families. Mol Aspects Med 34:386-395

49. Villa-Bellosta R, Sorribas V (2010) Compensatory regulation of the sodium/phosphate cotransporters NaPi-IIc (SCL34A3) and Pit-2 (SLC20A2) during Pi deprivation and acidosis. Pflugers Arch 459:499-508

50. Villa-Bellosta R, Ravera S, Sorribas V et al (2009) The $\mathrm{Na}^{+}-\mathrm{Pi}$ cotransporter PiT-2 (SLC20A2) is expressed in the apical membrane of rat renal proximal tubules and regulated by dietary Pi. Am J Physiol Renal Physiol 296:F691-F699

51. Moe OW (2009) PiT-2 coming out of the pits. Am J Physiol Renal Physiol 296:F689-F690
52. Segawa H, Yamanaka S, Ohno Y et al (2007) Correlation between hyperphosphatemia and type II Na-Pi cotransporter activity in klotho mice. Am J Physiol Renal Physiol 292:F769-F779

53. Giral H, Caldas Y, Sutherland E et al (2009) Regulation of rat intestinal Na-dependent phosphate transporters by dietary phosphate. Am J Physiol Renal Physiol 297:F1466-F1475

54. Bai L, Collins JF, Ghishan FK (2000) Cloning and characterization of a type III Na-dependent phosphate cotransporter from mouse intestine. Am J Physiol Cell Physiol 279:C1135-C1143

55. Marks J, Debnam ES, Unwin RJ (2010) Phosphate homeostasis and the renal-gastrointestinal axis. Am J Physiol Renal Physiol 299:F285-F296

56. Dermaku-Sopjani M, Sopjani M, Saxena A et al (2011) Downregulation of NaPi-IIa and NaPi-IIb Na-coupled phosphate transporters by coexpression of Klotho. Cell Physiol Biochem 28:251-258

57. Nielsen LB, Pedersen FS, Pedersen L (2001) Expression of type III sodium-dependent phosphate transporters/retroviral receptors mRNAs during osteoblast differentiation. Bone 28:160-166

58. Zoidis E, Ghirlanda-Keller C, Gosteli-Peter M et al (2004) Regulation of phosphate $(\mathrm{Pi})$ transport and $\mathrm{NaPi}-\mathrm{III}$ transporter (Pit-1) mRNA in rat osteoblasts. J Endocrinol 181:531-540

59. Lundquist P, Murer H, Biber J (2007) Type II Na+-Pi cotransporters in osteoblast mineral formation: regulation by inorganic phosphate. Cell Physiol Biochem 19:43-56

60. Yamashita T, Nifuji A, Furuya K et al (1998) Elongation of the epiphyseal trabecular bone in transgenic mice carrying a klotho gene locus mutation that leads to a syndrome resembling aging. $\mathrm{J}$ Endocrinol 159:1-8

61. Kawaguchi H, Manabe N, Miyaura C et al (1999) Independent impairment of osteoblast and osteoclast differentiation in klotho mouse exhibiting low-turnover osteopenia. J Clin Invest 104:229-237

62. Sasaki M, Hasegawa T, Yamada T et al (2013) Altered distribution of bone matrix proteins and defective bone mineralization in klotho-deficient mice. Bone 57:206-219

63. Kim HR, Nam BY, Kim DW et al (2013) Circulating alphaklotho levels in CKD and relationship to progression. Am J Kidney Dis 61:899-909

64. Seiler S, Rogacev KS, Roth HJ et al (2014) Associations of FGF23 and sKlotho with cardiovascular outcomes among patients with CKD stages 2-4. Clin J Am Soc Nephrol 9:1049-1058

65. Mathew S, Tustison KS, Sugatani T et al (2008) The mechanism of phosphorus as a cardiovascular risk factor in CKD. J Am Soc Nephrol 19:1092-1105

66. Hu MC, Shi M, Zhang J et al (2011) Klotho deficiency causes vascular calcification in chronic kidney disease. J Am Soc Nephrol 22:124-136

67. Yamada S, Tokumoto M, Tatsumoto N et al (2014) Phosphate overload directly induces systemic inflammation and malnutrition as well as vascular calcification in uremia. Am J Physiol Renal Physiol 306:F1418-F1428

68. Kitagawa M, Sugiyama H, Morinaga H et al (2013) A decreased level of serum soluble Klotho is an independent biomarker associated with arterial stiffness in patients with chronic kidney disease. PLoS One 8:e56695

69. Hu MC, Kuro-o M, Moe OW (2014) AlphaKlotho and vascular calcification: an evolving paradigm. Curr Opin Nephrol Hypertens 23:331-339

70. Fusaro M, Crepaldi G, Maggi S et al (2011) Vitamin K, bone fractures, and vascular calcifications in chronic kidney disease: an important but poorly studied relationship. J Endocrinol Invest 34:317-323

71. Civitelli R, Ziambaras K (2011) Calcium and phosphate homeostasis: concerted interplay of new regulators. J Endocrinol Invest $34: 3-7$ 